\title{
Pathogenic Trichomonas vaginalis cytotoxicity to cell culture monolayers
}

\author{
J F ALDERETE AND E PEARLMAN \\ From the Department of Microbiology, University of Texas Health Science Center at San Antonio, \\ San Antonio, Texas, USA
}

SUMMARY Exposure of monolayer cultures of human urogenital and vaginal (HeLa), human epithelial (HEp-2), normal baboon testicular (NBT), and monkey kidney (Vero) cells to live pathogenic Trichomonas vaginalis resulted in extensive disruption of monolayers. Trypan blue was taken up by all host cells released from cell monolayers, which indicated irreversible damage of these cell types by trichomonads. Time and dose related data on cytotoxicity kinetics were obtained using increasing ratios of parasites to cells. All cell types were most sensitive to trichomonads at a multiplicity of infection of one. Release of tritiated thymidine $\left({ }^{3} \mathrm{H}\right.$-thymidine $)$ of the deoxyribonucleic acid (DNA) of prelabelled host cells after incubation with $T$ vaginalis corroborated that extensive cytotoxicity was caused by pathogenic trichomonads in man. Only living parasites were cytotoxic, and no trichomonal toxic products were implicated in disruption of the cell monolayer cultures. A pathogenic bovine trichomonad, Tritrichomonas foetus KV-1, produced half as much cell damage as did $T$ vaginalis. Trichomonas tenax, a non-pathogenic member of the normal flora of the oral cavity in man, produced no measurable cytotoxicity to HeLa cells when compared with the pathogenic human trichomonads.

\section{Introduction}

Trichomonal vaginitis is a urogenital and vaginal infection caused by the protozoan parasite Trichomonas vaginalis. The disease is characterised by severe inflammation and discomfort, a foul smelling discharge, and tissue cytotoxicity in symptomatic women..$^{1-5}$ Most men appear asymptomatic and have little or no overt disease manifestations. ${ }^{35}$ Because of the complex aetiology of vaginal infections, the variety of symptoms, and the lack of a simple immunodiagnostic test many cases are misdiagnosed and untreated, 5 which contributes to the overall economic and emotional burden of this infection.

Tissues and cell culture systems from people infected with $T$ vaginalis have been examined, ${ }^{2}$ 6-10 but no mechanism responsible for host cell cytotoxicity has been found. The intimate interaction between trichomonads and host cells, as demonstrated by ultrastructural studies, ${ }^{11}$ has been suggested as a step leading to potential host cytopathogenicity. ${ }^{8}$ Equally important, extensive cytopathological changes and inhibition of cellular

Address for reprints: Dr John F Alderete, Department of Microbiology, University of Texas Health Science Center at San Antonio, 7703 Floyd Curl Drive, San Antonio, Texas 78284, USA

Accepted for publication 20 July 1983 division of cultured cells caused by trichomonal culture filtrates have been reported. ${ }^{2}$ A neuraminidase has been implicated in the pathogenesis of the bovine trichomonad, Tritrichomonas foetus, ${ }^{2}$ and this and other protozoan parasites are known to produce exoproteases during growth and multiplication. ${ }^{212-15}$ Studies on the interaction between pathogenic $T$ vaginalis or trichomonal culture filtrates and host cells are therefore essential for our understanding of possible mechanisms of pathogenesis. In this report we discuss the initial phase of our study which implicates predominantly contact dependent cytotoxicity in the interaction between parasite and host.

\section{Materials and methods}

GROWTH AND MAINTENANCE OF

TRICHOMONADS

$T$ vaginalis 2861617 was cultured in vitro in Diamond's trypticase-yeast-extract-maltose medium (pH 6.2) supplemented with $10 \%$ heat inactivated horse serum as previously described. ${ }^{17} 18$ Only organisms grown in vitro for less than one month after their arrival in our laboratory were used for all experiments unless otherwise stated. $T$ t foetus $\mathrm{KV}-1^{16}$ was used for comparative studies and treated similarly. Both trichomonal strains were pathogenic on 
subcutaneous inoculation of $5-10 \times 10^{6}$ organisms into the hind quarters of 6 week old BALB/c mice. ${ }^{18} 19$ Trichomonas tenax obtained from the American Type Culture Collection (ATCC; Rockville, Maryland, USA) was also used in this study, and was maintained as above in Diamond's trypticase-panmede-serum ${ }^{20}$ complex medium (North American Biologicals, Miami, Florida, USA). This organism did not produce any lesions in mice following subcutaneous challenge with trichomonads.

\section{CYTOTOXICITY OF CELL MONOLAYERS}

MEDIATED BY $T$ VAGINALIS

Human epithelial cells (HEp-2) and cells of human urogenital and vaginal origin (HeLa) were obtained from ATCC. African Green monkey kidney cells (Vero) and primary cultures of normal baboon testicular (NBT) cells were the kind gifts of Joan Ratner and Joel Baseman, respectively, of this department. Cells were seeded at a density of $20-30 \times 10^{3}$ into individual wells of Costar 96 well microtitre plates (Bellco, New Vineland, New Jersey, USA) to yield densities of $50 \times 10^{3}$ cells after overnight incubation. Cultures were incubated in $5 \%$ carbon dioxide at $37^{\circ} \mathrm{C}$ in Eagle's minimal essential medium (Grand Island Biologicals, Grand Island, New York, USA) supplemented with $10 \%$ fetal bovine serum (Kansas City Biologicals, Kansas City, Missouri, USA) with $100 \mathrm{U} / \mathrm{ml}$ penicillin $\mathrm{G}$ and $100 \mathrm{mg} / \mathrm{l}$ streptomycin.

Trichomonads in the logarithmic phase of growth ${ }^{17}$ were washed twice in phosphate buffered saline (PBS) (137 mmol/1 sodium chloride, $1.7 \mathrm{mmol} / \mathrm{l}$ potassium chloride, $4.6 \mathrm{mmol} / 1$ sodium phosphate, and $1.5 \mathrm{mmol} / 1$ potassium dihydrophosphate) and resuspended to desired densities in a medium mixture of 2:1 parts cell culture medium to trichomonal medium. ${ }^{8}$ The medium mixture did not adversely affect host cell or trichomonad viability during the time of the experiments, as shown by trypan blue exclusion or the release of radioactivity into culture supernate after cells had been labelled with ${ }^{3} \mathrm{H}$-thymidine. After gentle removal of the culture medium, a $0.1 \mathrm{ml}$ volume of parasite suspension in the medium mixture was added to the cell monolayers, each of which was incubated with different ratios of parasites to host cells for desired lengths of time. The wells were then gently (to avoid disruption of remaining monolayers) washed twice with PBS. The remaining cells were fixed to the polyvinyl microtitre well with $2 \%$ formaldehyde (final concentration) in PBS for 10 minutes at room temperature, ${ }^{21}$ and stained with $0 \cdot 13 \%$ crystal violet dissolved in a 5:2 (vol:vol) ethanol-formaldehyde solution. The stained material was subsequently washed twice with distilled water, the plates air dried, and the remaining stain solubilised in $1 \%$ sodium dodecylsulphate prepared in $50 \%$ ethanol. Individual wells were then scanned using a Dynatech MR580 MicroELISA autoreader spectrophotometer at $570 \mathrm{~nm}$ wavelength. The nature and extent of host cell damage caused by $T$ vaginalis was also assessed using phase contrast optics on a Zeiss IM30 inverted microscope. Each experiment was repeated at least three times. Data are represented as the mean and standard deviations of a representative experiment containing no less than four samples for each condition.

To assess further the trichomonal mediated effect on host cells, parasites and cells were incubated in close contact as recently described. ${ }^{15}$ After overnight radiolabelling of cell culture monolayers with $0.5 \mathrm{mCi}^{3} \mathrm{H}$-thymidine (specific activity $71 \mathrm{Ci} / \mathrm{mmol}$; Schwarz/Mann, Spring Valley, New York, USA) 100 $\times 10^{3}$ cells in $1 \mathrm{ml}$ of medium mixture were added to sterile conical centrifuge tubes. Washed trichomonads at designated densities were then added and, after gentle mixing, the parasite and cell suspension was centrifuged at $500 \times g$ for 5 minutes and the supernate discarded. An $0.1 \mathrm{ml}$ amount of the medium mixture was then added without disrupting the pellet, and the tubes were incubated at $37^{\circ} \mathrm{C}$ in $5 \%$ carbon dioxide for various lengths of time. The pellet was then resuspended in $2 \mathrm{ml}$ PBS, recentrifuged at $500 \times g$ for 10 minutes, and a $1 \mathrm{ml}$ sample of supernate was measured for radioactivity using scintillation spectrometry.

\section{CULTURE FILTRATE FRACTIONS USED FOR} CYTOTOXICITY ASSAYS

Trichomonal culture supernate was filtered through a $0.45 \mu \mathrm{m}$ Gelman acrodisk (Gelman Science Inc, Ann Arbor, Michigan, USA) and concentrated threefold by lyophilisation to about $30 \%$ the original volume. The concentrated filtrate was then mixed with cell culture medium in a ratio of $1: 2$, and this mixture was used in cytotoxicity assays. Enrichment for toxic products possibly present in very low amounts in culture supernate was also accomplished by sequential ultrafiltration through XM-100, PM-10, and UM-2 Diaflo membranes (Amicon, Lexington, Massachusetts, USA) which have exclusion limits of $\geqslant 100,000(100 \mathrm{~K}), 10 \mathrm{~K}-100 \mathrm{~K}$, and $1 \mathrm{~K}-10 \mathrm{~K}$ molecular weight respectively. The UM-2 ultrafiltrate was dialysed, lyophilised, and resuspended in distilled water. Each fraction was concentrated tenfold from the initial volume and mixed as above in tissue culture medium. All samples were used immediately after processing.

FIXATION OF T VAGINALIS ORGANISMS The extensively washed $T$ vaginalis organisms were fixed with glutaraldehyde as recently described. ${ }^{22}$ 
After the trichomonads were washed with PBS they were resuspended in culture medium to indicated densities for cytotoxicity studies.

\section{Results}

\section{DETECTION OF HOST CELL CYTOTOXIC}

\section{ACTIVITY}

To measure any cytopathogenic effects of $T$ vaginalis on eukaryotic host cells, we used modified microassays based on systems used for other microbial models. ${ }^{1521}$ Cells remaining in the wells of microtitre plates after incubation with parasites under various experimental conditions were stained, and a direct correlation was shown between the amount of
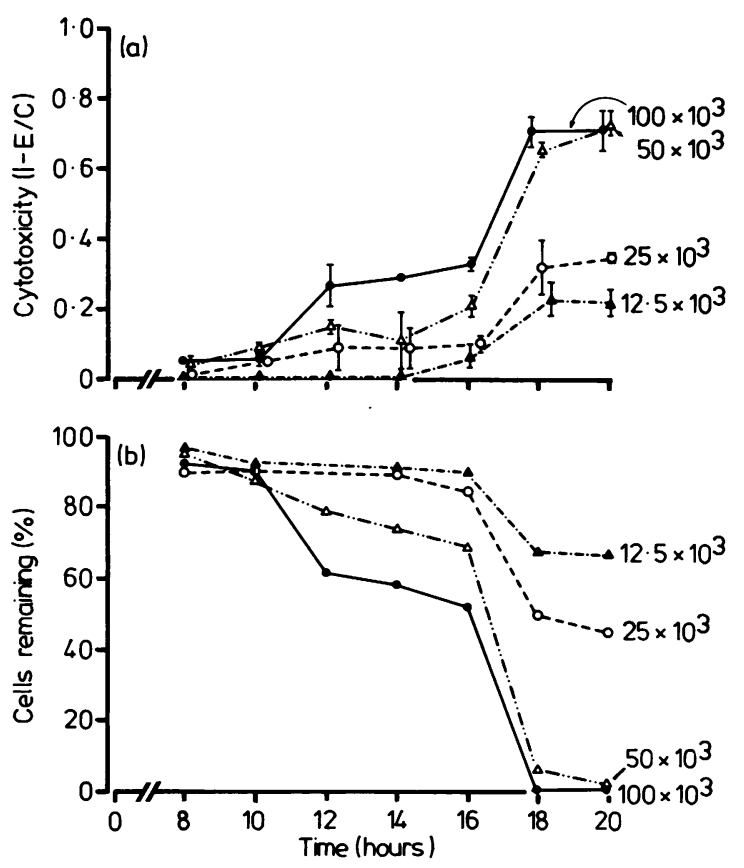

FIG 1 Disruption of HeLa cell monolayers by incubation with several densities of pathogenic $T$ vaginalis for 20 hours. a) Cytotoxicity determined, after staining of remaining fixed cells on microtitre plate wells, by subtracting from $1 \cdot 0$ the ratio of absorbence at $570 \mathrm{~nm}$ of experimental (E) to control (C) samples. Absorbence in experimental samples at maximum cytotoxicity was about a quarter of that in control samples. Each well contained about $50 \times 10^{3} \mathrm{HeLa}$ cells, and parasite to host cell ratios for increasing trichomonal densities were thus 1:4, 1:2, 1:1, and 2:1 respectively. b) Correlation of cytotoxicity with the extent of removal of cells from monolayer cultures. Maximum cytotoxicity as represented by $50 \times 10^{3} T$ vaginalis (parasite: cell ratio $1: 1$ ) at 18 hours showed no detectable cells remaining in microtitre wells on microscopical examination. stained cellular material and absorbence at $570 \mathrm{~nm}$. Fig 1 represents the kinetics of damage to HeLa cells by various densities of trichomonads. Increasing incubation time enhanced the cytotoxic effect for each parasite density, as shown by loss of staining. An inoculum size of at least $50 \times 10^{3} T$ vaginalis organisms, which represented a multiplicity of infection of one, produced maximum disruption (about $100 \%$ loss) of the monolayer within 18 hours (fig 1a). All cytoxicity measurements of experimental (E) samples were indexed to those of control (C) samples, for which no loss of cells from the microtitre plate wells was evident under the assay conditions used, and subtracted from $1 \cdot 0$.

Fig lb illustrates the correlation between the extent of cell disruption, as measured by decreased absorbence readings, with the percentage of cells remaining in the confluent monolayer as seen in fig la. Incubation of cells with $50 \times 10^{3}$ trichomonads at a ratio of 1:1 caused complete removal of host cells, as measured visually using phase contrast microscopy. The maximum cytotoxicity of about 0.7 as represented in figure 1a therefore correlated with $100 \%$ cell detachment (fig $1 \mathrm{~b}$ ).

Because the assay conditions and medium combinations resulted in about a doubling of the tricho-

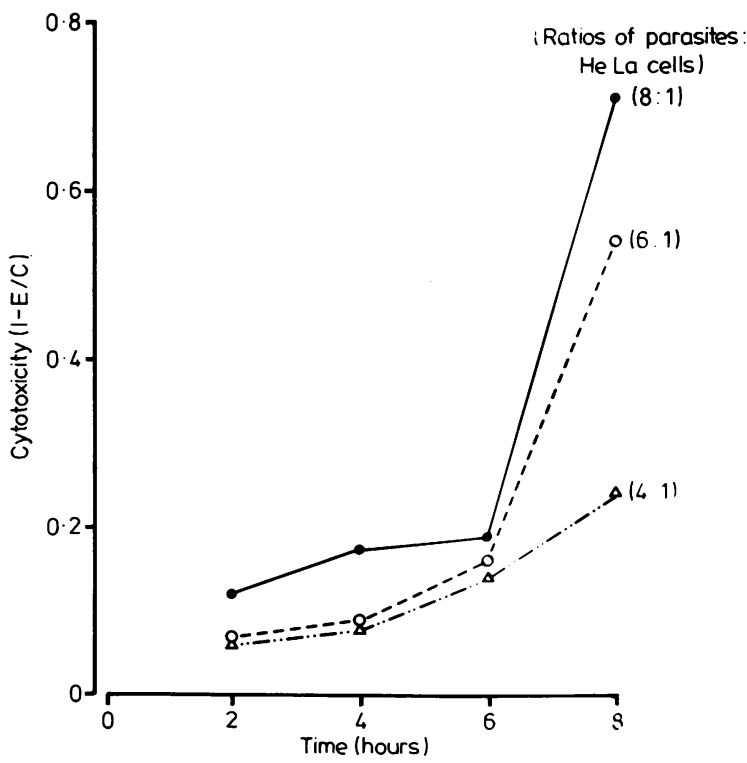

FIG 2 Representative cytotoxicity using increased ratios of $T$ vaginalis to HeLa cells incubated for eight hours. $A$ ratio of $4: 1$ represents about $100 \times 10^{3}$ trichomonads with a monolayer of $25 \times 10^{3} \mathrm{HeLa}$ cells. $\mathrm{E} / \mathrm{C}=$ ratio of absorbence readings at $570 \mathrm{~nm}$ for experimental $(E)$ versus control $(C)$ samples after staining of fixed microtitre wells. 
monads in this extended time, we evaluated trichomonal cytotoxicity using higher parasite densities but shorter incubation times. As was expected, an initial number of more than $200 \times 10^{3}$ parasites, giving trichomonad:cell ratios of $4: 1,6: 1$, and $8: 1$ respectively, produced maximum cytotoxicity within eight hours (fig 2). Initiation of disruption of cell monolayers, therefore, appeared to be a function of trichomonal densities in the parasite and host cell incubation mixture.

ROLE IN CYTOTOXICITY OF MEDIUM pH, LIVING TRICHOMONADS, AND TOXIC MOLECULES IN CULTURE FILTRATE IN CYTOTOXICITY

To establish that a decrease in $\mathrm{pH}$ of the medium was not responsible for disruption of cell monolayers, the $\mathrm{pH}$ was monitored over the extended time of 20 hours and is shown in fig 3a (insert). In duplicate samples containing parasite: host cell ratios of $1: 1$ the medium $\mathrm{pH}$ was adjusted to $7 \cdot 0$ throughout the 20 hour period and the same level of cell monolayer disruption was seen as shown in fig 1. Furthermore, as illustrated in fig 3a, no cytotoxicity was demonstrable in HeLa cell cultures incubated for 20 hours in the medium mixture without trichomonads when the medium was maintained at either $\mathrm{pH} 7 \cdot 2$ or $\mathrm{pH}$ $6 \cdot 0$.
Figure $3 \mathrm{~b}$ shows that there was no cytotoxicity when fixed organisms or culture filtrate were used, nor did $T$ vaginalis fixed with glutaraldehyde produce any disruption of $\mathrm{HeLa}$ cell monolayers. Similar results were obtained when supernate of late logarithmic phase organisms were incubated with cell cultures for $\mathbf{2 0}$ hours (data not shown). Attempts to enrich for a substance toxic to HeLa cells by fractionation and processing filtrates were unsuccessful using this indicator system, and repeatedly produced little or no cytotoxicity.

The release of HeLa cells from the cell monolayers after co-incubation with $T$ vaginalis was also monitored microscopically using phase-contrast optics. Reculture of the liberated HeLa cells was not attempted because trypan blue uptake by all liberated host cells was indicative of host cell death in this assay. Cytotoxicity of HeLa cells, therefore, appeared to result from irreversible cell damage caused by trichomonads. Furthermore, mechanical disruption of the cell monolayers by trichomonads as suggested by others ${ }^{9}$ was not apparent throughout the short or extended times used.

\section{ANALYSIS OF CYTOTOXICITY OF DIFFERENT TRICHOMONAL SPECIES}

$T t$ foetus $\mathrm{KV}-1$ is a pathogenic bovine trichomonad, ${ }^{2}$ and we felt that its analysis by our

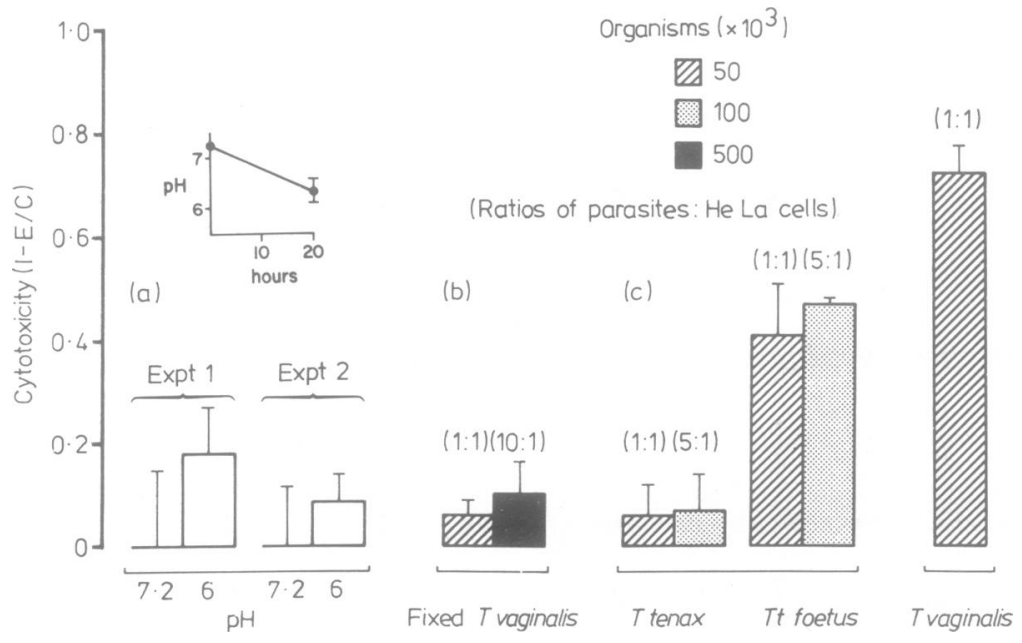

FIG 3 Disruption of HeLa cell culture monolayer by $T$ vaginalis under various experimental conditions. a) Effect of uninoculated culture medium maintained at given $\mathrm{pH}$ values for 20 hours on removal of cells from the microtitre well (two experiments). Insert shows kinetics of $\mathrm{pH}$ of cell cultures containing $50 \times 10^{3}$ cells inoculated with the same number of trichomonads. b) Lack of cytotoxicity of parasites after glutaraldehyde fixation. c) Differential cytotoxicity of $T t$ foetus and $T$ tenax compared with representative $T$ vaginalis strain $286 . E / C=$ ratio of absorbence readings at $570 \mathrm{~nm}$ for experimental $(E)$ versus control $(C)$ samples after staining of fixed microtitre wells. 
assay might detect similarities or differences in host cell cytotoxicity by various trichomonal species. Fig $3 \mathrm{c}$ shows lower levels of cell monolayer disruption by higher densities of $T t$ foetus than of $T$ vaginalis 286 and little or no cytotoxicity in experiments using $T$ tenax when compared with pathogenic $T$ vaginalis. Greater densities of $T$ tenax than of $T$ vaginalis gave no more than $10 \%$ of the latter's cytotoxicity.

Furthermore, isolates from infected women but grown for less than one week in our laboratory were similarly evaluated for their cytopathogenic potential using this assay system. Results identical with those observed for strain 286 were obtained (data not shown). Additionally, representative cloned isolates of $T$ vaginalis $286^{18}$ possessed equivalent levels of cytotoxicity to those of the parent heterogeneous population. Finally, human trichomonal strains implicated as possessing varying levels of pathogenicity 19 all yielded maximal cell monolayer disruption as did strain 286.

\section{RELEASE OF TRITIUM BY HOST CELLS AFTER CONTACT WITH T VAGINALIS}

To show further the disruption of HeLa cells by $T$ vaginalis, we examined the release of ${ }^{3} \mathrm{H}$-thymidine from radiolabelled host cells incubated with trichomonads. This procedure has been successfully used in another protozoan parasite system to monitor direct contact damage to eukaryotic cells. ${ }^{15}$ The host cell DNA was pulse chase labelled with precursor to establish that depletion of accumulated ${ }^{3} \mathrm{H}$-thymidine pools in HeLa cells had not caused the release of radioactivity in the co-incubation experiments. Figure 4 shows that parasite contact with radio-

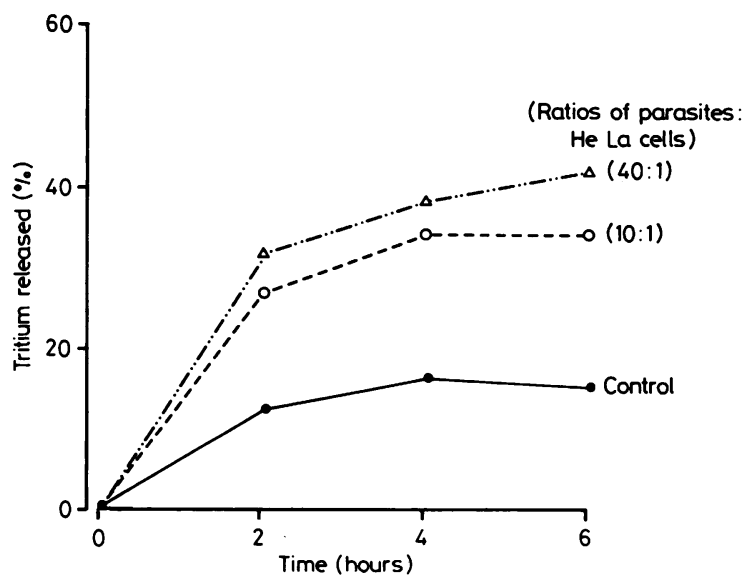

FIG 4 Course of ${ }^{3} \mathrm{H}$ release from $\mathrm{HeLa}$ cells after incubation with several densities of pathogenic $T$ vaginalis. Control shows release of radioactivity from HeLa cells in the absence of trichomonads. labelled HeLa cells resulted in appreciable release of radioactive material. A ratio of 10:1 organisms to HeLa cells showed greater release than from HeLa cells incubated without trichomonads. An increased uptake of trypan blue by HeLa cells during this experiment was also seen. Consistent with previous data (fig $3 b$ ) $T$ vaginalis fixed with glutaraldehyde did not enhance release of radiolabelled DNA above control levels (data not shown). A four times greater inoculum size (40:1 ratio of parasites to HeLa cells) resulted in only slightly higher amounts of radioactivity being released into the supernate, suggesting that there was maximum cell damage with the ratios used previously under different experimental conditions (fig 2).

\section{CYTOTOXICITY TO VARIOUS CELL CULTURE LINES}

The development of an assay to measure cytotoxicity to HeLa cell monolayers allowed us to examine the possible detrimental effect of $T$ vaginalis on other unrelated cell lines. Fig 5 shows the differential cytotoxicity of $T$ vaginalis to cells of different origin and animal species. After incubation for 20 hours with a low parasite inoculum (giving a parasite:cell ratio of $1: 4)$, Vero cells appeared most refractory, while HEp-2 cells were highly susceptible to trichomonal killing. At parasite densities equivalent to a multiplicity of infection of one, however, all cell types appeared equally susceptible, resulting in total disruption of cell monolayers.

\section{Discussion}

Information on the nature and extent of tissue cytotoxicity caused by pathogenic $T$ vaginalis ${ }^{6-10}$ is crucial to our overall understanding of the actual mechanism(s) of pathogenesis in the relation between host and parasite, and for this a reproducible method of measuring cytotoxicity to host cells is essential. We therefore developed a spectrophotometric assay used for other microbial models ${ }^{2}$ to measure disruption of host cell monolayers by trichomonads.

Cytotoxicity after co-incubation of live trichomonads with the various cell monolayers was dramatic and resulted in total loss of cells after extended exposure to parasites (figs 1,2 , and 5 ). Irreversible cell damage and death was shown by trypan blue uptake in detached cells, and these observations correlated with tritium release by host cell DNA after exposure to $T$ vaginalis (fig 4$)$. The absence of cytotoxicity in both assays when fixed trichomonads or concentrated fractions of culture filtrate were used (fig 3) implicated contact dependent mechanisms. Examination of the cell monolayers throughout the incubation period (after 

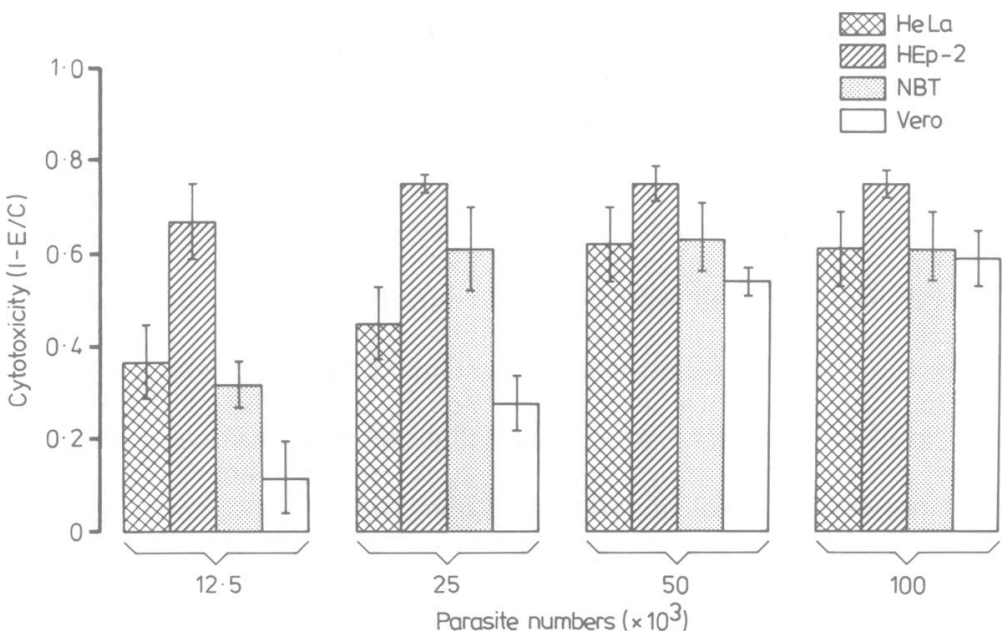

FIG 5 Differential cytotoxicity of monolayer cultures each containing $50 \times 10^{3}$ cells of four cell lines incubated with several densities of pathogenic $T$ vaginalis for 20 hours. $E / C=$ ratio of absorbence readings at $570 \mathrm{~nm}$ for experimental (E) versus control (C) samples after fixing and staining microtitre wells.

addition of the highly motile trichomonads) indicated that mechanical disruption ${ }^{82}$ was not responsible for cytotoxicity under these experimental conditions.

The presence of caseinase activity in sonicates and filtrates of $T$ vaginalis has recently been documented. ${ }^{12} 22$ Culture supernates or concentrated fractions obtained by ultrafiltration did not, however, produce any alteration in cell culture monolayers, even though proteolytic activity in certain fractions and supernate was retained (unpublished observations). Similar results have been reported by other investigators. ${ }^{10}$ Lack of an effect by filtrate on cells, however, could also be explained by very low levels of toxin, masking of toxic moieties by medium components, or a selective effect by parasite products on host cells during certain stages in their cell cycle. The reported close ju position of parasites with host cells, ${ }^{11}$ however, does not totally exclude possible undefined $T$ vaginalis exoproducts from the initial cytotoxicity. Thus, while our data differ from those of others who have readily detected toxic substances (presumably of parasite origin) in culture filtrates, ${ }^{2923}$ we recognise that alternative assay systems may be necessary to evaluate more fully the role of toxins in cytopathogenicity, especially as elaborated cytotoxic substances such as neuraminidases and proteases appear relevant in tissue cytotoxicity with $T t$ foetus. ${ }^{2}{ }^{14}$ Alternatively, differences in toxicity with harmful medium or parasite molecules in trichomonal culture filtrate may be a function of the variety of cell cultures from different tissues, animals, and people which have been used in past studies.

The non-removal of HeLa cells from the monolayer by non-pathogenic $T$ tenax (fig 3c) confirms the usefulness of the assay system as a tool for future dissection of biochemical events leading to severe cytopathogenicity. Differences in the degree of cytotoxicity between human and bovine pathogenic trichomonads further illustrate the potential of this assay system for assessing pathogenicity levels of different strains of $T$ vaginalis. For example, this type of assay may allow for analysis of mutant strains of pathogenic trichomonads and subsequent delineation of precise virulence determinants. To date, no non-virulent human $T$ vaginalis strains are available. Human trichomonads previously characterised as moderately pathogenic ${ }^{19}$ yielded identical results in this assay, and those described as attenuated ${ }^{19}$ have been found to give lesions in mice inoculated subcutaneously with higher parasite densities. ${ }^{18}$ None the less, work is in progress to define the differential cytotoxic effects among these different trichomonal species.

Although HeLa cells were used in this study because of their human urogenital origin, the similarity in the extent of cytotoxicity of all cell types used was of interest (fig 5). The less sensitive nature of Vero cells at low multiplicities of infection may indicate unique membrane properties of this cell type that are less accommodating to $T$ vaginalis or its toxic products. These differences may be important during future studies aimed at dissection of cyto- 
pathogenic mechanisms. Overall, our results agree with those of numerous groups ${ }^{81023}$ concerning a mechanism of cell destruction dependent on contact. We feel, therefore, that the development of a highly sensitive quantitative assay, which uses standard cell culture methods with defined cell lines to measure cytopathogenicity mediated by $T$ vaginalis should extend our knowledge of the biology of this parasite and of parasite biochemical targets which lead to pathogenesis.

This work was supported by Public Health Service grant AI 18766 from the National Institutes of Health to JFA. We thank Grace Wagner for her expert secretarial advice and assistance.

\section{References}

1. Honigberg BM. Trichomonads of importance in human medicine. In: Kreier JP, ed. Parasitic protozoa, vol 2. New York: Academic Press, 1978:275-392.

2. Honigberg BM. Biological and physiological factors affecting pathogenicity of trichomonads. In: Biochemistry and Physiology of Protozoa, vol 2. New York: Academic Press, 1979:409-27.

3. Kreiger JN. Urologic aspects of trichomoniasis. Invest Urol 1981; 18:411-7.

4. Rein MF, Chapel TA. Trichomoniasis, candidiasis, and the minor venereal diseases. Clin Obstet Gynecol 1975; 18:73-88.

5. Spence MR, Hollander DH, Smith J, McCaig L, Sewell D, Brockman M. The clinical and laboratory diagnosis of Trichomonas vaginalis infection. Sex Transm Dis 1980; 7: 168-72.

6. Christian RT, Miller NF, Ludovici PP, Riley GM. A study of Trichomonas vaginalis in human cell culture. Am J Obstet Gynecol 1963;85:947-54.

7. Frost JK. Trichomonas vaginalis and cervical epithelial changes. Ann NY Acad Sci 1962;97:792-9.
8. Heath JP. Behavior and pathogenicity of Trichomonas vaginalis in epithelial cell cultures. Br J Vener Dis 1981;57: 106-17.

9. Hogue MJ. The effect of Trichomonas vaginalis on tissue culture cells. American Journal of Hygiene 1943;37:142-52.

10. Kotcher E, Hoogasian AC. Cultivation of Trichomonas vaginalis Donné, 1837, in association with tissue cultures [Abstract]. J Parasitol 1957; 43 suppl: 39.

11. Nielsen MH, Nielsen R, Ludvik J. On the ultrastructure of Trichomonas vaginalis Donné. J Microscopie (Paris) 1966;5:229-50.

12. Coombs GH. Proteinases of Leishmania mexicana and other flagellate protozoa. Parasitology 1982;84:149-55.

13. McLaughlin J, Faubert G. Partial purification and some properties of a neutral sulfhydryl and acid proteinase from Entamoeba histolytica. Can J Microbiol 1977;23:420-5.

14. McLaughlin J, Muller M. Purification and characterization of a low molecular weight thiol proteinase from the flagellate protozoan Tritrichomonas foetus. J Biol Chem 1979;254: 1526-33.

15. Ravdin JE, Croft BY, Guerrant RL. Cytopathogenic mechanisms of Entamoeba histolytica. J Exp Med 1980;152: 377-90.

16. Müller M, Meingassner JG, Miller WA, Ledger WJ. Three metronidazole-resistant strains of Trichomonas vaginalis from the USA. Am J Obst Gynecol 1980; 138:808-12.

17. Peterson KM, Alderete JF. Host plasma proteins on the surface of pathogenic Trichomonas vaginalis. Infect Immun 1982;37:755-62.

18. Alderete JF. Antigen analysis of several pathogenic strains of Trichomonas vaginalis. Infect Immun 1983;39:1041-7.

19. Honigberg BM, Livingston MC, Frost JK. Pathogenicity of fresh isolates of Trichomonas vaginalis: "the mouse assay" versus clinical and pathologic findings. Acta Cytol 1966;10: 353-61.

20. Diamond LS. Techniques of axenic culture of Entomoeba histolytica schaudinni, 1403 and $E$ histolytica-like amebae. $J$ Parasitol 1968;54: 1047-56.

21. Gentry MK, Dalrymple JM. Quantitative microtiter cytotoxicity assay for Shigella toxin. J Clin Microbiol 1980; 12: 361-6.

22. Peterson KM, Alderete JF. Acquisition of $\alpha_{1}$-antitrypsin by a pathogenic strain of Trichomonas vaginalis. Infect Immun 1983; 40:640-60.

23. Kulda J, Honigberg BM. Behavior and pathogenicity of Trichomonas vaginalis in chick liver cell cultures. J Protozool 1969; 16:479-95. 